\title{
The dominance of pandemic serovars of Vibrio parahaemolyticus in expatriates and sporadic cases of diarrhoea in Thailand, and a new emergent serovar (O3 : K46) with pandemic traits
}

Correspondence Oralak Serichantalergs oralaks@afrims.org
Received 13 October 2006 Accepted 17 January 2007

\author{
Oralak Serichantalergs, ${ }_{1}^{1}$ Nurul Amin Bhuiyan, ${ }^{2}$ Gopinath Balakrish Nair, ${ }^{2}$ \\ Orapan Chivaratanond, ${ }^{1}$ Apichai Srijan, ${ }^{1}$ Ladaporn Bodhidatta, ${ }^{1}$ \\ Sinn Anuras $^{3}$ and Carl J. Mason ${ }^{1}$ \\ ${ }^{1}$ Armed Forces Research Institute of Medical Sciences (AFRIMS), Bangkok 10400, Thailand \\ ${ }^{2}$ International Centre for Diarrhoeal Disease Research (ICDDR,B), Dhaka 1212, Bangladesh \\ ${ }^{3}$ Bumrungrad Hospital, Bangkok 10110, Thailand
}

\begin{abstract}
Vibrio parahaemolyticus is a major cause of gastroenteritis worldwide. A total of $95 \mathrm{~V}$. parahaemolyticus isolates belonging to 23 different serovars were identified in a case-control study of expatriates and Thai adults from 2001 to 2002 in Thailand. Fifty-two per cent of isolates (49/95) were resistant to ampicillin and sulfisoxazole, but all isolates were susceptible to ciprofloxacin and trimethoprim-sulfamethoxazole, two antibiotics commonly used to treat traveller's diarrhoea. All isolates were positive for the species-specific toxR gene, and 91 and 5 were positive for the thermostable direct haemolysin $(t d h)$ gene and the $t d h$-related (trh) gene, respectively. Sixty-five isolates were assigned to the pandemic group of $V$. parahaemolyticus by a group-specific PCR and the presence of the orf8 gene. The pandemic isolates belonged to three recognized serovars (O3 : K6, O1 : K25, O1 : KUT) and a new serovar, O3 : K46. This new serovar harboured pandemic traits. PFGE analysis revealed that all pandemic isolates including serovar $\mathrm{O} 3$ : K46 were closely related and clearly distinct from the non-pandemic isolates. In summary, three well-known serovars of pandemic $V$. parahaemolyticus isolates were identified as a major cause of diarrhoea in Thailand and a new $V$. parahaemolyticus isolate, serovar $\mathrm{O} 3: \mathrm{K} 46$, with pandemic traits was detected.
\end{abstract}

\section{INTRODUCTION}

Vibrio parahaemolyticus, a Gram-negative halophilic bacterium, is responsible for human gastroenteritis worldwide and sporadic cases and outbreaks occur regularly in Asia as well as in other countries (Bag et al., 1999; DePaola et al., 2003; Joseph et al., 1982; Wong et al., 2000; Yeung \& Boor, 2004). Virulence of $V$. parahaemolyticus is associated with the production of a thermostable direct haemolysin (TDH), TDH-related haemolysin (TRH) (Honda et al., 1991; Nishibuchi et al., 1985; Nishibuchi et al., 1989) and urease enzyme (Suthienkul et al., 1995). The genes encoding these factors, $t d h$, trh and ure, are therefore used as genetic markers indicative of the virulence of strains (Kim et al., 1999; Suthienkul et al., 1995).

As many as 75 different combinations of the somatic $(\mathrm{O})$ and capsular $(\mathrm{K})$ antigens have been identified (Ishibashi et al., 2000). In 1996, the emergence of $V$. parahaemolyticus serovar O3 : K6 was reported in Calcutta, India (Okuda

Abbreviation: GS, group-specific. et al., 1997). Subsequently, O3 : K6 clones have disseminated throughout Southeast Asia, Atlantic and Gulf coasts of the USA (Daniels et al., 2000; Matsumoto et al., 2000; Okuda et al., 1997) and more recently in Europe (Martinez-Urtaza et al., 2004), Africa (Ansaruzzaman et al., 2005) and South America (Gonzalez-Escalona et al., 2005). It has been shown that the group-specific (GS) sequence of the toxRS operon and the presence of ORF8 in the filamentous phage $\mathrm{f} 237$ are specific for pandemic O3: K6 clones, and these genetic markers are used to distinguish between pandemic and non-pandemic traits (Matsumoto et al., 2000; Nasu et al., 2000). Later, several more serovars, $\mathrm{O} 4: \mathrm{K} 68, \mathrm{O} 1: \mathrm{K} 25, \mathrm{O} 1: \mathrm{K} 26$ and O1 : KUT, were reported to share closely related genetic patterns to pandemic serovar O3 : K6 (Bhuiyan et al., 2002; Chowdhury et al., 2004; Matsumoto et al., 2000; Wong et al., 2000).

In 2001-2002, the Department of Enteric Diseases, AFRIMS, Thailand, conducted a case-control study of acute diarrhoea in expatriates and Thai adults. V. parahaemolyticus was the third leading pathogen isolated from this study. This finding provided the impetus to examine 
these $V$. parahaemolyticus isolates by molecular techniques to understand better the epidemiological relatedness and significance of this pathogen in expatriate and Thai adults presenting with diarrhoea.

\section{METHODS}

Enrolment and specimen collection. After obtaining written informed consent, stool specimens or rectal swabs, and demographic and clinical information were collected from acute diarrhoea patients (417 expatriates and 400 Thai adults) and non-diarrhoea controls at Bumrungrad Hospital in Bangkok from January 2001 to December 2002. Expatriates were travellers and resident foreigners from developed countries seen at Bumrungrad Hospital. Sixty-five per cent $(33 / 51)$ of the expatriates with $V$. parahaemolyticus infection were in Thailand for $\leqslant 1$ month. Controls were patients seen at the hospital with no reported diarrhoea during the previous 2 weeks. One control was selected for each case (417 asymptomatic expatriate samples and 400 asymptomatic Thai adults). All specimens were transported to the laboratory and processed within $2-4 \mathrm{~h}$ of collection.

Isolation and identification. All samples were examined for $V$. parahaemolyticus and other enteric pathogens (Salmonella spp., Shigella spp., Vibrio spp., Plesiomonas spp., Aeromonas spp., Campylobacter spp. and pathogenic Escherichia coli) by standard bacteriological methods (Holt et al., 1994) and DNA hybridization assays (Echeverria et al., 1989). For V. parahaemolyticus isolation, fresh stool samples or rectal swabs transported in $10 \mathrm{ml}$ modified Cary-Blair $(0.16 \%$ agar $)$ medium were suspended in $3 \mathrm{ml}$ normal saline solution and inoculated directly onto selective medium, thiosulfate/citrate/bile salt/sucrose (TCBS) agar. A portion of each faecal suspension was enriched in $5 \mathrm{ml}$ alkaline peptone water containing $0.5 \% \mathrm{NaCl}$, followed by overnight incubation at $37{ }^{\circ} \mathrm{C}$, and then subcultured again on TCBS. Presumptive identification of $V$. parahaemolyticus was determined by the appearance of typical blue-green colonies on TCBS agar. Suspected colonies were picked for further biochemical testing (Holt et al., 1994), including a urease test.

Antibiotic susceptibility testing. All $V$. parahaemolyticus isolates were tested for antimicrobial susceptibility by a standard disc diffusion method on Mueller-Hinton II agar (National Committee for Clinical Laboratory Standards, 2000a). The antibiotic discs (BD Diagnostic Systems) used were: ampicillin, chloramphenicol, kanamycin, gentamicin, tetracycline, trimethoprim-sulfamethoxazole, nalidixic acid, ciprofloxacin and sulfisoxazole. In the absence of Clinical and Laboratory Standards Institute (formerly NCCLS) definitive standards for interpreting $V$. parahaemolyticus, zone diameters were determined and recorded as sensitive, intermediate or resistant according to interpretive standards established for Vibrio cholera and members of the Enterobacteriaceae. E. coli ATCC 25922 was used as a control organism (National Committee for Clinical Laboratory Standards, 2000b).

Serotyping. Confirmed V. parahaemolyticus isolates were serotyped by agglutination using a commercial set of $\mathrm{O}$ and $\mathrm{K}$ antisera (Denka Seiken) according to the manufacturer's instructions.

PCR. PCR assays for the species-specific toxR gene and two virulence genes ( $t d h$ and $t r h$ ) were performed as described previously using boiled cultures of $V$. parahaemolyticus as the source of DNA template (Kim et al., 1999; Suthienkul et al., 1995). The GS-PCR and PCR for the orf8 gene were performed using specific primers reported previously to detect toxRS sequences unique to the pandemic O3 : K6 clone of $V$. parahaemolyticus and the orf8 sequence of phage f237, respectively (Matsumoto et al., 2000; Nasu et al., 2000).
PFGE. NotI-PFGE was performed on all $95 \mathrm{~V}$. parahaemolyticus isolates as described previously using the PulseNet Protocol (Centers for Disease Control and Prevention, 2004). The images of DNA band patterns were analysed for cluster analysis using BIONUMERICS software version 3.5 (Applied Maths) based on the Dice similarity coefficient and unweighted pair-group method with arithmetic averages.

\section{RESULTS AND DISCUSSION}

\section{Epidemiology and clinical data}

Ninety-five isolates of $V$. parahaemolyticus were recovered. Fifty were from expatriates with diarrhoea and 43 from Thai adults with diarrhoea. Two isolates were identified from non-diarrhoea controls: one from an expatriate and the other from a Thai adult. The finding of similar numbers of expatriates and Thai adults infected with $V$. parahaemolyticus (51/417 expatriates and 44/400 Thai adults) suggests that both populations are equally susceptible to infection with the species. Epidemiological data showed that all of the expatriates with $V$. parahaemolyticus stayed in Thailand for at least $48 \mathrm{~h}$ before the onset. The incubation period of $V$. parahaemolyticus is between 4 and $30 \mathrm{~h}$ (Besser et al., 2003), suggesting that most expatriates potentially acquired the infection in Thailand. Of the 93 diarrhoea cases with $V$. parahaemolyticus, $74 \%$ reported watery diarrhoea whilst $26 \%$ reported loose stools; only one case of bloody diarrhoea was noted. Other symptoms reported included abdominal pain $(89 \%)$, nausea (77\%), vomiting (61\%), fatigue $(55 \%)$ and fever $(53 \%)$. No significant difference was found between self-reported symptoms and pandemic versus non-pandemic isolates from cases.

\section{Serotyping}

Twenty-three different combinations of $\mathrm{O}$ and $\mathrm{K}$ antigens were found and included three previously recognized pandemic group serovars, O3 : K6, O1 : K25 and O1 : KUT, accounting for $54 \%(51 / 95), 11 \%(10 / 95)$ and $5 \%(5 / 95)$, respectively (Table 1$)$. One pandemic isolate, $\mathrm{O} 3: \mathrm{K} 6$, was found from an expatriate in the control group. The non-pandemic isolates belonged to 19 different $\mathrm{O}: \mathrm{K}$ antigen combinations. These findings confirmed the presence of the same pandemic clone among clinical isolates as described in a previous study from southern Thailand in 2000-2002 (Vuddhakul et al., 2006). However, serovars O4 : K68, O1 : K41 and O4 : K12, which were identified in pandemic clones in 1998 and 1999 from southern Thailand, were not detected in this study (Chowdhury et al., 2000a; Laohaprertthisan et al., 2003). The prevalence of pandemic isolates of serotype O3 : K6 in expatriates and Thai adults was $71 \%(36 / 51)$ and $34 \%(15 / 44)$, respectively. This may be explained by different patterns of food consumption but, unfortunately, dietary information was not collected. Furthermore, little information regarding the existence of pandemic isolates in environmental and food samples is available in Thailand (Vuddhakul et al., 2000). 
Table 1. Serotypes, genotypes and PFGE typing of V. parahaemolyticus isolates from Thailand in 2001-2002

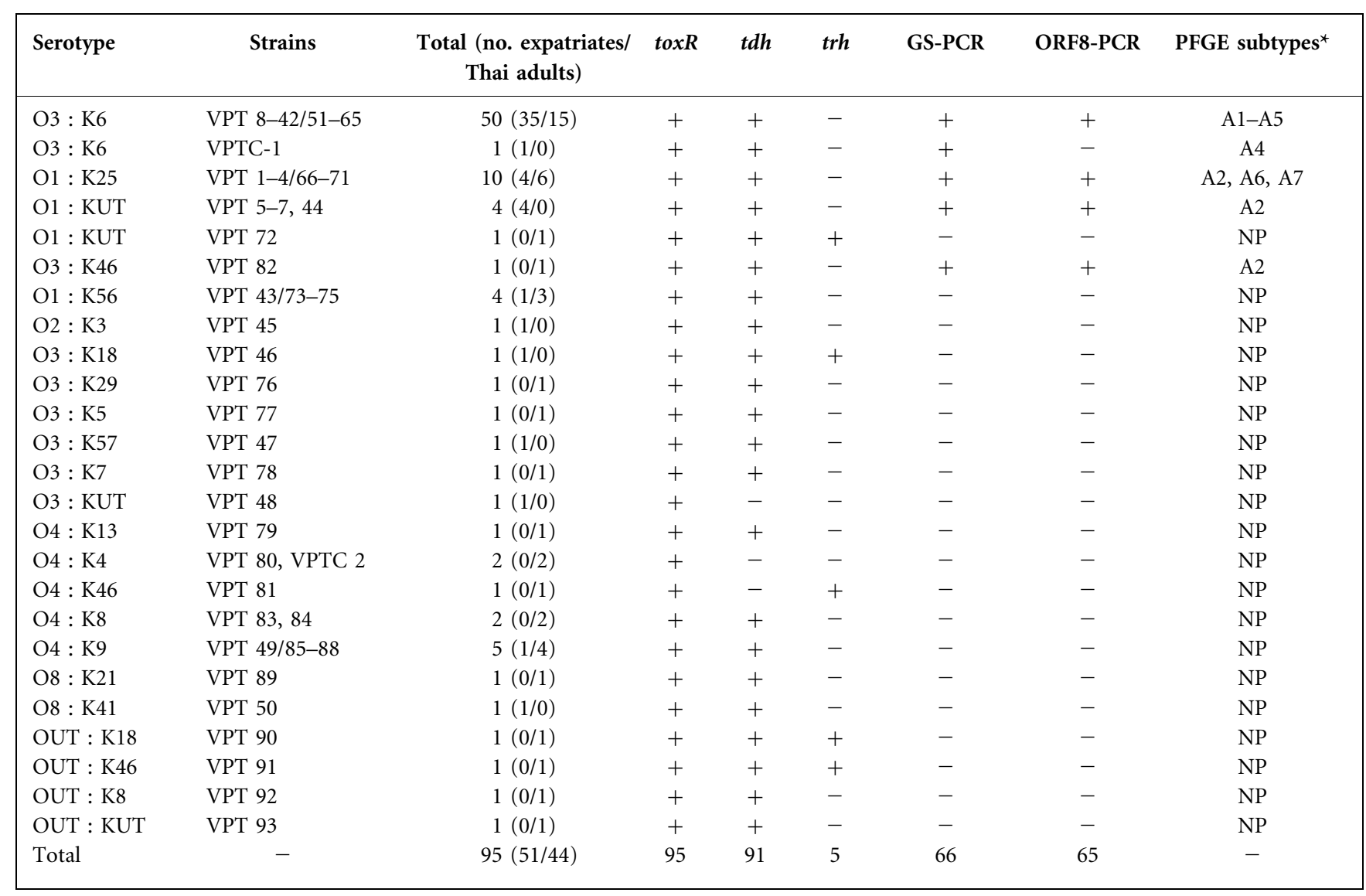

${ }^{\star} \mathrm{NP}$, Non-pandemic cluster.

\section{Antimicrobial susceptibility}

Fifty-two per cent (49/95) of $V$. parahaemolyticus isolates were resistant to ampicillin and sulfisoxazole. None of the isolates were resistant to chloramphenicol, kanamycin, gentamicin, tetracycline, trimethoprim-sulfamethoxazole, nalidixic acid or ciprofloxacin. Thus all $V$. parahaemolyticus isolates tested were susceptible to antibiotics commonly used to treat traveller's diarrhoea.

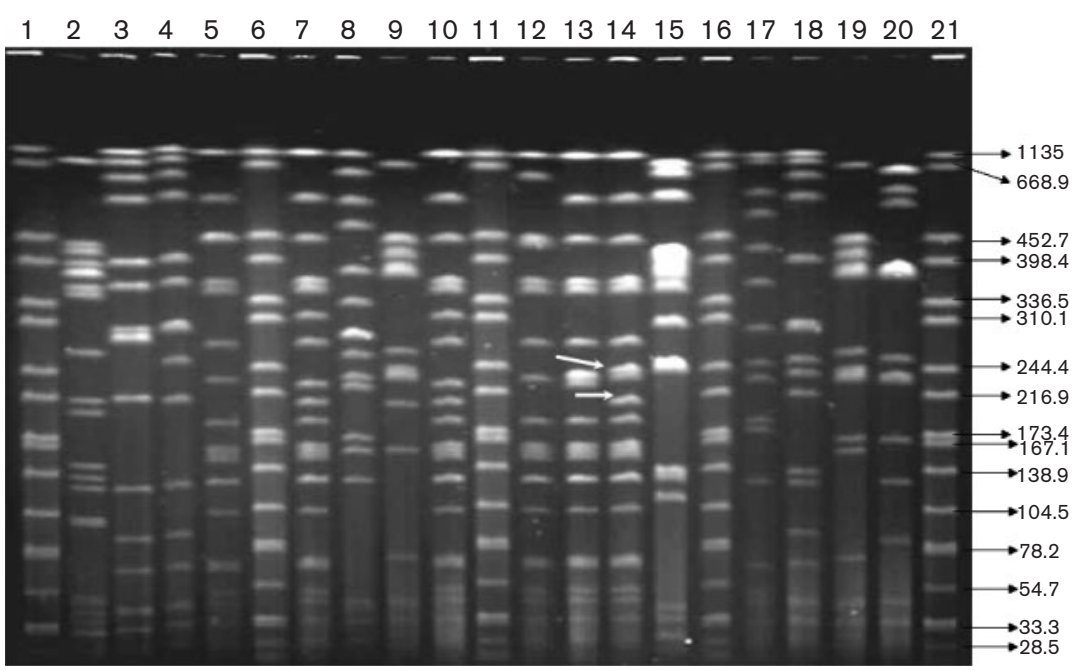

Fig. 1. Notl-PFGE of selected V. parahaemolyticus isolates with different serovars. Lanes 1 , $6,11,16$ and 21, molecular mass marker of Salmonella serotype Branderup $\mathrm{H} 9812$; lanes $2-4,8,9,15$ and 17-20, different serovars of non-pandemic isolates (VPT 77, 85, 86, 92, 83, 75, 81, 87, 91 and 76); lanes 7, 10 and 13, pandemic isolates of serovar O3 : K6 (VPT 63-65); lanes 5 and 12, pandemic isolates of serovars $\mathrm{O} 1$ : KUT and O1: K25 (VPT 72 and $71)$; lane 14 , an isolate of serovar $\mathrm{O} 3$ : K46 (VPT 82). 


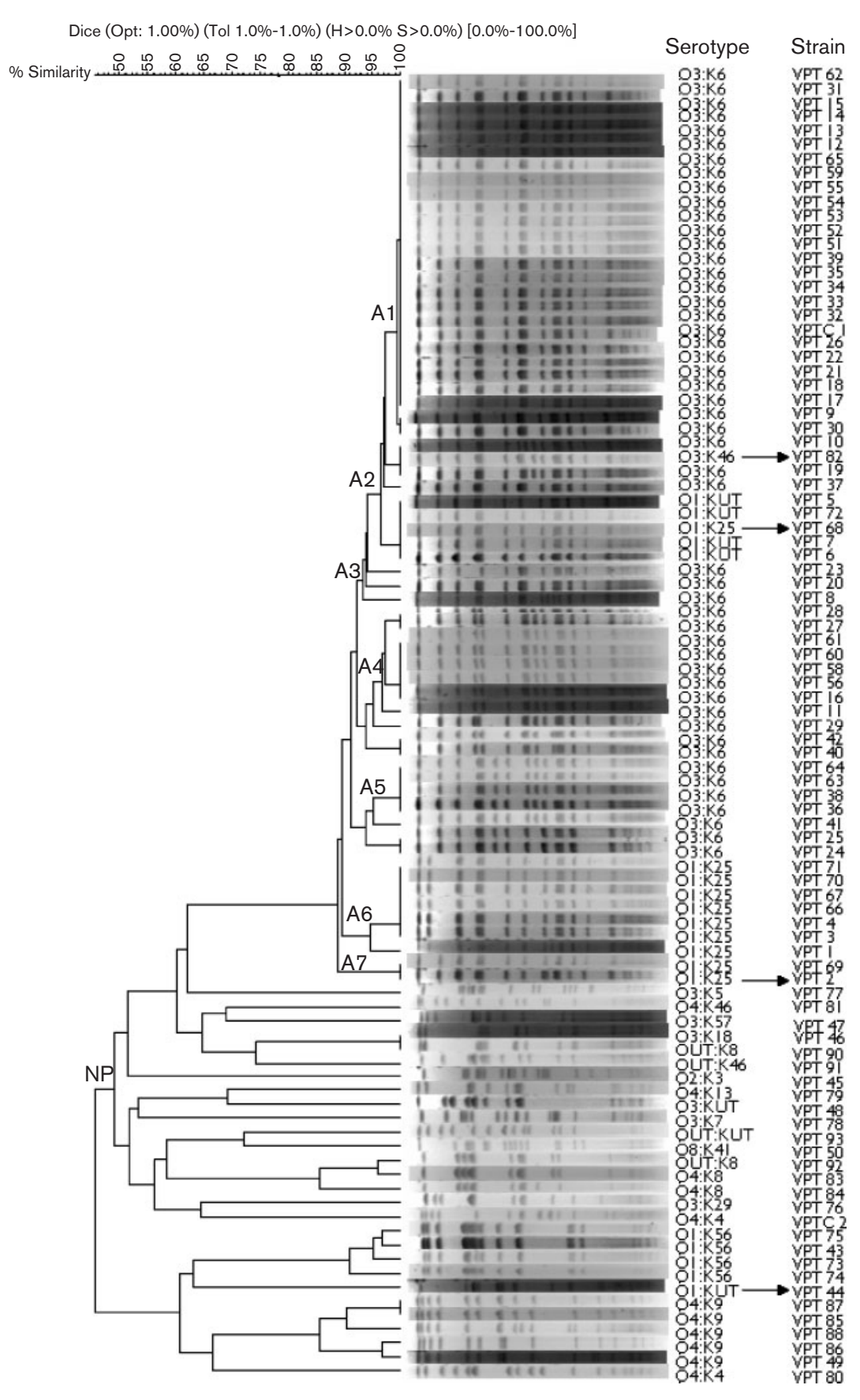

Fig. 2. Dendrogram of $93 \mathrm{~V}$. parahaemolyticus isolates from Thailand in 2001-2002. All pandemic isolates of serovars $\mathrm{O} 3: \mathrm{K} 6$, O1: KUT, O1: K25 and $\mathrm{O} 3: \mathrm{K} 46$ were in subtypes A1-A7 (90-100\% similarity). All non-pandemic isolates were in the non-pandemic (NP) cluster ( $<50 \%$ similarity).

\section{Genotypic traits}

Table 1 shows that all $V$. parahaemolyticus isolates were positive for the species-specific gene toxR, 91 were positive for $t d h$, five for $t r h$ and four for both $t d h$ and $t r h$. All five trh gene-positive isolates were urease positive. Interestingly, three isolates (two from diarrhoea cases and one asymptomatic control) were negative for both $t d h$ and trh. GS-PCR and ORF8-PCR demonstrated that $71 \%(66 / 95)$ of isolates carried the GS sequence of the toxRS operon unique to the pandemic strains of $V$. parahaemolyticus; these isolates, except for one, were also positive for the orf 8 gene. All of the pandemic isolates of the three known serovars O3: K6, $\mathrm{O} 1: \mathrm{K} 25$ and O1 : KUT were positive for $t d h$, GS-PCR and ORF8-PCR with the exception of one isolate, serovar O1 : KUT, that was negative for GS-PCR and ORF8-PCR. By definition, this isolate should therefore not be classified as pandemic. Interestingly, one isolate, serovar O3 : K46, from a Thai case, positive for toxR, $t d h$, GS-PCR and ORF8-PCR, harboured the pandemic traits. A clinical Thai isolate, serovar O3 : $\mathrm{K} 46$, was previously reported as a nonpandemic strain in 1999 (Okura et al., 2003). None of the 
five isolates carrying the trh gene were positive for GS-PCR and ORF8-PCR.

As previously reported, this study confirmed that the majority of clinical $V$. parahaemolyticus isolates have the $t d h$ gene and lack the trh gene (Laohaprertthisan et al., 2003; Martinez-Urtaza et al., 2004; Suthienkul et al., 1995; Vuddhakul et al., 2000). Furthermore, isolates from two acute diarrhoea cases were negative for both the $t d h$ and trh genes. Our investigation did not detect any other enteric bacterial pathogens, parasites (Giardia and Cryptosporidium) or viruses (rotavirus, norovirus, adenovirus and astrovirus) in these two acute diarrhoea cases. This suggested the possibility of either other unknown pathogens or other virulence mechanisms in V. parahaemolyticus.

\section{DNA fingerprint and cluster analysis}

PFGE was performed on all $95 \mathrm{~V}$. parahaemolyticus isolates, but two isolates showed poorly resolved patterns and were omitted from the cluster analysis. Fig. 1 shows NotI-PFGE patterns of selected $V$. parahaemolyticus isolates. An isolate of serovar O3 : K46 (lane 14) showed two DNA band shifts of approximately 240 and $217 \mathrm{~kb}$ compared with serovar O3 : K6 (lane 13). Cluster analysis and a dendrogram combined with serotype results revealed that all of the pandemic isolates of serovars $\mathrm{O} 3: \mathrm{K} 6, \mathrm{O} 1: \mathrm{K} 25$, O1 : KUT and O3 : K46 had a high degree of similarity (90-100\%), as illustrated in Fig. 2. Serotyping and PFGE of the $V$. parahaemolyticus isolate serovar O3: K46 was repeated twice with reproducible results. From the dendrogram, the pandemic isolates were classified into seven subtypes (A1-A7). The newly emerged serovar O3 : K46 belonged to subtype A2. All pandemic isolates of serovar O1 : K25 clustered in subtypes A6 and A7 with one exception. As expected, the isolate of serovar O1 : KUT that was negative by GS-PCR and ORF8-PCR was not classified in the pandemic cluster $(<50 \%$ similarity). The non-pandemic isolates clustered separately from pandemic isolates.

In this study, we combined both genotypic characterization and molecular typing to gain a better understanding of strain diversity of $V$. parahaemolyticus in Thailand. The combination of serotyping and molecular methods for detection of genetic markers such as virulence genes, GS sequence, orf8 gene and PFGE was valuable for epidemiological surveillance in distinguishing pandemic isolates from non-pandemic isolates. Our results coupled with those of other researchers suggest that serovars of pandemic $V$. parahaemolyticus are changing over time (Chowdhury et al., 2000b; Laohaprertthisan et al., 2003; Matsumoto et al., 2000), but pandemic isolates of serovar O3: K6 still maintain the ability to survive in the environment. The detection of a single isolate of $V$. parahaemolyticus serovar O3 : K46 having pandemic traits should provide the impetus for continued surveillance of $V$. parahaemolyticus in Thailand and elsewhere.

\section{ACKNOWLEDGEMENTS}

This work was supported by the US Department of Defense Global Emerging Infections System (GEIS), Washington DC, USA, and by the core funds of the Centre for Health and Population Research, Bangladesh (ICDDR,B). We gratefully acknowledge their support and commitment to our research efforts. We thank Siriporn Sornsakrin and Ovath Thonglee for their help in enrolment and specimen collection. We also thank Caroline Fukuda for her proofreading and constructive input to the discussion. The views expressed here are those of the authors and not to be construed as reflecting the views of the US Department of Defense or Army.

\section{REFERENCES}

Ansaruzzaman, M., Lucas, M., Deen, J. L., Bhuiyan, N. A., Wang, X. Y., Safa, A., Sultana, M., Chowdhury, A., Nair, G. B. \& other authors (2005). Pandemic serovars (O3: K6 and O4: K68) of Vibrio parahaemolyticus associated with diarrhea in Mozambique: spread of the pandemic into the African continent. J Clin Microbiol 43, 2559-2562.

Bag, P. K., Nandi, S., Bhadra, R. K., Ramamurthy, T., Bhattacharya, S. K., Nishibuchi, M., Hamabata, T., Yamasaki, S., Takeda, Y. \& Nair, G. B. (1999). Clonal diversity among recently emerged strains of Vibrio parahaemolyticus $\mathrm{O} 3$ : K6 associated with pandemic spread. J Clin Microbiol 37, 2354-2357.

Besser, J., Beebe, J. \& Swaminathan, B. (2003). Investigation of foodborne and waterborne disease outbreaks. In Manual of Clinical Microbiology, pp. 162-181. Edited by P. R. Murray, E. J. Baron, M. A. Pfaller, J. H. Jorgensen \& R. H. Yolken. Washington, DC: American Society for Microbiology.

Bhuiyan, N. A., Ansaruzzaman, M., Kamruzzaman, M., Alam, K., Chowdhury, N. R., Nishibuchi, M., Faruque, S. M., Sack, D. A., Takeda, Y. \& Nair, G. B. (2002). Prevalence of the pandemic genotype of Vibrio parahaemolyticus in Dhaka, Bangladesh, and significance of its distribution across different serotypes. J Clin Microbiol 40, 284-286.

Centers for Disease Control and Prevention (2004). One-day (24$28 \mathrm{~h}$ ) standardized laboratory protocol for molecular subtyping of Escherichia coli O157 : H7, non-typhoidal Salmonella serotypes, and Shigella sonnei by pulsed-field gel electrophoresis (PFGE). In PulseNet 8th Annual Update Meeting, San Diego, CA, USA, 27-30 April 2004. Centers for Disease Control and Prevention.

Chowdhury, N. R., Chakraborty, S., Eampokalap, B., Chaicumpa, W., Chongsa-Nguan, M., Moolasart, P., Mitra, R., Ramamurthy, T., Bhattacharya, S. K. \& other authors (2000a). Clonal dissemination of Vibrio parahaemolyticus displaying similar DNA fingerprint but belonging to two different serovars (O3: K6 and $\mathrm{O} 4: \mathrm{K} 68)$ in Thailand and India. Epidemiol Infect 125, 17-25.

Chowdhury, N. R., Chakraborty, S., Ramamurthy, T., Nishibuchi, M., Yamasaki, S., Takeda, Y. \& Nair, G. B. (2000b). Molecular evidence of clonal Vibrio parahaemolyticus pandemic strains. Emerg Infect Dis $\mathbf{6}$, 631-636.

Chowdhury, N. R., Stine, O. C., Morris, J. G. \& Nair, G. B. (2004). Assessment of evolution of pandemic Vibrio parahaemolyticus by multilocus sequence typing. J Clin Microbiol 42, 1280-1282.

Daniels, N. A., MacKinnon, L., Bishop, R., Altekruse, S., Ray, B., Hammond, R. M., Thompson, S., Wilson, S., Bean, N. H. \& other authors (2000). Vibrio parahaemolyticus infections in the United States, 1973-1998. J Infect Dis 181, 1661-1666.

DePaola, A., Ulaszek, J., Kaysner, C. A., Tenge, B. J., Nordstrom, J. L., Wells, J., Puhr, N. \& Gendel, S. M. (2003). Molecular, serological, and virulence characteristics of Vibrio parahaemolyticus isolated from environmental, food, and clinical sources in North America and Asia. Appl Environ Microbiol 69, 3999-4005. 
Echeverria, P., Taylor, D. N., Seriwatana, J., Brown, J. E. \& Lexomboon, U. (1989). Examination of colonies and stool blots for detection of enteropathogens by DNA hybridization with eight DNA probes. J Clin Microbiol 27, 331-334.

Gonzalez-Escalona, N., Cachicas, V., Acevedo, C., Rioseco, M. L., Vergara, J. A., Cabello, F., Romero, J. \& Espejo, R. T. (2005). Vibrio parahaemolyticus diarrhea, Chile, 1998 and 2004. Emerg Infect Dis 11, 129-131.

Holt, J. G., Krieg, N. R., Sneath, P. H. A., Staley, J. T. \& Williams, S. T. (1994). Bergey's Manual of Determinative Bacteriology, 9th edn. Baltimore, MA: Williams \& Wilkins.

Honda, T., Abad-Lapuebla, M. A., Ni, Y. X., Yamamoto, K. \& Miwatani, T. (1991). Characterization of a new thermostable direct haemolysin produced by a Kanagawa-phenomenon-negative clinical isolate of Vibrio parahaemolyticus. J Gen Microbiol 137, 253-259.

Ishibashi, M., Ohta, K., Shimada, T., Honda, T., Sugiyama, J. \& Miwatani, Y. (2000). Current status of OK serotype combinations of Vibrio parahaemolyticus. Nippon Saikingaku Zasshi 55, 539-541.

Joseph, S. W., Colwell, R. R. \& Kaper, J. B. (1982). Vibrio parahaemolyticus and related halophilic Vibrios. Crit Rev Microbiol 10, 77-124.

Kim, Y. B., Okuda, J., Matsumoto, C., Takahashi, N., Hashimoto, S. \& Nishibuchi, M. (1999). Identification of Vibrio parahaemolyticus strains at the species level by PCR targeted to the toxR gene. J Clin Microbiol 37, 1173-1177.

Laohaprertthisan, V., Chowdhury, A., Kongmuang, U., Kalnauwakul, S., Ishibashi, M., Matsumoto, C. \& Nishibuchi, M. (2003). Prevalence and serodiversity of the pandemic clone among the clinical strains of Vibrio parahaemolyticus isolated in southern Thailand. Epidemiol Infect 130, 395-406.

Martinez-Urtaza, J., Lozano-Leon, A., DePaola, A., Ishibashi, M., Shimada, K., Nishibuchi, M. \& Liebana, E. (2004). Characterization of pathogenic Vibrio parahaemolyticus isolates from clinical sources in Spain and comparison with Asian and North American pandemic isolates. J Clin Microbiol 42, 4672-4678.

Matsumoto, C., Okuda, J., Ishibashi, M., Iwanaga, M., Garg, P., Rammamurthy, T., Wong, H. C., Depaola, A., Kim, Y. B. \& other authors (2000). Pandemic spread of an O3 : K6 clone of Vibrio parahaemolyticus and emergence of related strains evidenced by arbitrarily primed PCR and toxRS sequence analyses. J Clin Microbiol 38, 578-585.

Nasu, H., lida, T., Sugahara, T., Yamaichi, Y., Park, K. S., Yokoyama, K., Makino, K., Shinagawa, H. \& Honda, T. (2000). A filamentous phage associated with recent pandemic Vibrio parahaemolyticus O3: K6 strains. J Clin Microbiol 38, 2156-2161.

National Committee for Clinical Laboratory Standards (2000a). Performance Standards for Antimicrobial Disk Susceptibility Tests.
Approved Standard, M2-A7. Villanova, PA: National Committee for Clinical Laboratory Standards.

National Committee for Clinical Laboratory Standards (2000b). Performance Standards for Antimicrobial Disk Susceptibility Testing. Information supplement, M100-S10. Villanova, PA: National Committee for Clinical Laboratory Standards.

Nishibuchi, M., Ishibashi, M., Takeda, Y. \& Kaper, J. B. (1985). Detection of the thermostable direct hemolysin gene and related DNA sequences in Vibrio parahaemolyticus and other Vibrio species by the DNA colony hybridization test. Infect Immun 49, 481-486.

Nishibuchi, M., Taniguchi, T., Misawa, T., Khaeomanee-lam, V., Honda, T. \& Miwatani, T. (1989). Cloning and nucleotide sequence of the gene $(t r h)$ encoding the hemolysin related to the thermostable direct hemolysin of Vibrio parahaemolyticus. Infect Immun 57, 2691-2697.

Okuda, J., Ishibashi, M., Hayakawa, E., Nishino, T., Takeda, Y., Mukhopadhyay, A. K., Garg, S., Bhattacharya, S. K., Nair, G. B. \& Nishibuchi, M. (1997). Emergence of a unique O3 : K6 clone of Vibrio parahaemolyticus in Calcutta, India, and isolation of strains from the same clonal group from Southeast Asian travelers arriving in Japan. $J$ Clin Microbiol 35, 3150-3155.

Okura, M., Osawa, R., Iguchi, A., Arakawa, E., Terajima, J. \& Watanabe, H. (2003). Genotypic analyses of Vibrio parahaemolyticus and development of a pandemic group-specific multiplex PCR assay. $J$ Clin Microbiol 41, 4676-4682.

Suthienkul, O., Ishibashi, M., lida, T., Nettip, N., Supavej, S., Eampokalap, B., Makino, M. \& Honda, T. (1995). Urease production correlates with possession of the trh gene in Vibrio parahaemolyticus strains isolated in Thailand. J Infect Dis 172, 1405-1408.

Vuddhakul, V., Chowdhury, A., Laohaprertthisan, V., Pungrasamee, P., Patararungrong, N., Thianmontri, P., Ishibashi, M., Matsumoto, C. \& Nishibuchi, M. (2000). Isolation of a pandemic O3 : K6 clone of a Vibrio parahaemolyticus strain from environmental and clinical sources in Thailand. Appl Environ Microbiol 66, 2685-2689.

Vuddhakul, V., Soboon, S., Sunghiran, W., Kaewpiboon, S., Chowdhury, A., Ishibashi, M., Nakaguchi, Y. \& Nishibuchi, M. (2006). Distribution of virulent and pandemic strains of Vibrio parahaemolyticus in three molluscan shellfish species (Meretrix meretrix, Perna viridis, and Anadara granosa) and their association with foodborne disease in southern Thailand. J Food Prot 69, 2615-2620.

Wong, H. C., Liu, S. H., Ku, L. W., Lee, I. Y., Wang, T. K., Lee, Y. S., Lee, C. L., Kuo, L. P. \& Shih, D. Y. (2000). Characterization of Vibrio parahaemolyticus isolates obtained from foodborne illness outbreaks during 1992 through 1995 in Taiwan. J Food Prot 63, 900-906.

Yeung, P. S. \& Boor, K. J. (2004). Epidemiology, pathogenesis, and prevention of foodborne Vibrio parahaemolyticus infections. Foodborne Pathog Dis 1, 74-88. 